\title{
The advanced clinical practice pharmacy role and its implementation to practice in England
}

\author{
Tanvi Choudhary (D) \& Roger Newham \\ College of Medical and Dental Sciences, University of Birmingham, United Kingdom
}

\section{Keywords}

Advanced Clinical Practice (Pharmacy)

Advanced Practice

Pharmacists

\author{
Correspondence \\ Roger Newham \\ School of Nursing \\ Institute of Clinical Sciences \\ College of Medical and Dental Sciences \\ Medical School Building \\ University of Birmingham \\ Edgbaston, B15 2TT \\ Birmingham, UK \\ r.newham@bham.ac.uk
}

\begin{abstract}
Objectives: Advanced clinical practice (ACP) (pharmacy) aims to address workforce challenges within the rapidly changing, complex National Health Service (NHS) landscape in England. This review explores the current role, scope of practice and impact of ACP, with a focus on pharmacists. Methods: An integrative review across three databases from April 2019 to June 2019. Key criterion for inclusion was ACP and pharmacist in England. Key findings: Thirteen articles were used. Four key themes identified: ACP scope of practice and benefits; facilitators, challenges and barriers to ACP role implementation; role implementation and sustainability; and the patient's perspective. Most studies found it difficult to formally evaluate the impact of ACP. Positive anecdotal feedback was often reported. Conclusion: To further develop and sustain ACP, it is essential for future work to focus on evaluating impact of the role.
\end{abstract}

\section{Introduction}

Advanced practice across various professions is already an established concept that appears to be gaining interest and acceptance globally within all healthcare sectors (Nuffield Trust, 2016; Officer, Cumming \& McBride-Henry, 2019). The multi-professional Advanced Clinical Practice (ACP) role is a rapidly emerging role in England with Health Education England (HEE) envisaging the role across multi-professions, and all healthcare sectors (2015). HEE describe that the primary consideration of where an ACP role should be placed is where it can make the greatest impact, acknowledging that this may mean working outside of traditional boundaries. There is also a growing body of evidence demonstrating ACP input in primary care, such as improving accessibility of services and saving on cost (Casey et al., 2017), improved quality of care (Carnwell \& Daly, 2003) and patient satisfaction (Horrocks, Anderson \& Salisbury, 2002).
The Fédération Internationale Pharmaceutique/ International Pharmaceutical Federation (FIP), a global body representing pharmacy and pharmaceutical sciences, published a first of its kind report, providing a baseline of recognising advanced pharmacy practice (FIP, 2015). The report found that the advancement in practice is a growing global trend, with pharmacy becoming an increasingly complex, clinical and patient-facing profession. Although global, the role is not yet recognised in every country and there is a disparity with what constitutes advanced pharmacy practice and the scope of practice.

There is not a globally agreed upon definition of ACP, however HEE define ACP in England as:

'Advanced clinical practice is delivered by experienced, registered health and care practitioners. It is a level of practice characterised by a high degree of autonomy 
and complex decision making. This is underpinned by a master's level award or equivalent that encompasses the four pillars of clinical practice, leadership and management, education and research, with demonstration of core capabilities and area specific clinical competence.

Advanced clinical practice embodies the ability to manage clinical care in partnership with individuals, families and carers. It includes the analysis and synthesis of complex problems across a range of settings, enabling innovative solutions to enhance people's experience and improve outcomes'

[HEE, 2017: p.8]

Many qualified pharmacists continue their education to complete various postgraduate clinical qualifications. Two years post-registration, pharmacists are eligible to undertake independent prescribing training. Independent prescribers practice autonomously, and are responsible for the clinical assessment, diagnosis and the clinical management of a patient, aligning with the competencies of the 'clinical practice' HEE ACP pillar (General Pharmaceutical Council, 2019).

Given the recent recognition of the multidisciplinary ACP role in England, which includes pharmacists and the fact that the pharmacy profession has an existing advanced practice role recognised by the Royal Pharmaceutical Society (RPS) (2013), this review aims to explore the current role and scope of ACP (pharmacy) and the contribution and impact it makes. This review is timely within the rapidly changing, complex landscape of the National Health Service (NHS), substantiated by the key document, 'Advancing pharmacy education and training: a review', published by HEE (2019) mentioning the ACP role.

\section{Methods}

Integrative reviews can be used to identify, critique and synthesise current, relevant evidence to improve healthcare practice, inform research and policy. Such reviews uniquely include experimental and nonexperimental types of research for a broader understanding of a topic (Whittemore \& Knafl, 2005). An initial scoping exercise identified limited literature available due to the recent development of the standardised ACP role. It was therefore prudent to consider all types of research available.

\section{Data source and search strategy}

The Whittemore and Knafl (2005) guidelines for integrative reviews were followed. A comprehensive literature search was undertaken firstly using the databases Medline, ProQuest and Web of Science up to June 2019. The following search terms were used: advanced practice pharmacist, advanced clinical practitioner, ACP, pharmacist, advanced practice, advanced clinical pharmacist, role, scope, evaluate, impact, assess and analysis. These terms were combined with appropriate Boolean operators. In addition, hand searching by snowball and citation methods were used.

The search resulted in 180 articles. Exclusions were determined before the search, guided by initial scoping of the literature. Exclusions were duplicate articles, not in English, not advanced practice pharmacist focussed, advanced practitioners from professions other than pharmacy, and advanced pharmacy practice roles outside of English healthcare settings.

\section{Study selection}

Publications were screened by title and abstract and those deemed irrelevant were excluded. Publications were independently extracted by the first author and an independent reviewer who also, with the second author, checked the extracted data. Opinion articles written for peer-reviewed journals, although the lowest level of evidence, were included, providing context from the perspective of an expert working within the role or environment.

As suggested by Whittemore and Knafl (2005), a thematic approach was identified to analyse the data, prior to undertaking the review. Thematic analysis of the data was guided by Braun and Clarke (2006) to address the review aim. This included familiarisation of the data, followed by coding, reviewing, defining and naming the themes.

\section{Results}

A total of thirteen articles were included (Figure A). Of these articles, six were research studies (five qualitative studies and one observational study), three were commentaries in peer reviewed journals, three were professional body reports and one was a research report (Table I). 
Table I: Data abstraction

\begin{tabular}{|c|c|c|c|c|}
\hline Reference & Article/Study Objective & Practice Setting & Method & Key Findings \\
\hline $\begin{array}{l}\text { Barnes, E., Ashraf, I., \& Din, A. } \\
\text { (2017) }\end{array}$ & $\begin{array}{l}\text { To explore the new roles } \\
\text { for clinical pharmacists in } \\
\text { general practice }\end{array}$ & General Practice & $\begin{array}{l}\text { Comment article in } \\
\text { peer reviewed } \\
\text { journal }\end{array}$ & $\begin{array}{l}\text { The ACP role is new and therefore difficult to } \\
\text { assess impact however, the advantages are } \\
\text { thought to be similar to those by advanced nurse } \\
\text { practitioners }\end{array}$ \\
\hline $\begin{array}{l}\text { Royal Pharmaceutical } \\
\text { Society [RPS] (2013) }\end{array}$ & $\begin{array}{l}\text { To provide a framework } \\
\text { for Advanced Pharmacy } \\
\text { Practice }\end{array}$ & All settings & $\begin{array}{l}\text { Professional } \\
\text { Framework }\end{array}$ & $\begin{array}{l}\text { Competency framework allowing practitioners to } \\
\text { identify level of practice and areas they wish to } \\
\text { develop }\end{array}$ \\
\hline $\begin{array}{l}\text { Pearce, C., \& Breen, B. } \\
\text { (2018) }\end{array}$ & $\begin{array}{l}\text { To discuss the evolving role } \\
\text { of ACP in outpatient clinics }\end{array}$ & Outpatient clinics & $\begin{array}{l}\text { Comment article in } \\
\text { peer reviewed } \\
\text { journal }\end{array}$ & $\begin{array}{l}\text { Supporting ACP roles can help in recruiting and } \\
\text { retaining health professionals. Experience, skills, } \\
\text { competence and education is integral to the } \\
\text { role, along with competency framework, } \\
\text { governance, regulation and accreditation }\end{array}$ \\
\hline $\begin{array}{l}\text { Health Education England } \\
\text { [HEE] (2017) }\end{array}$ & $\begin{array}{l}\text { To provide a framework } \\
\text { for Advanced Clinical } \\
\text { Practice }\end{array}$ & All settings & $\begin{array}{l}\text { Professional } \\
\text { Framework }\end{array}$ & $\begin{array}{l}\text { Defines and sets the standard for level and } \\
\text { education of multi-professional ACP. Guidance } \\
\text { to employers on when and how to implement } \\
\text { the role. }\end{array}$ \\
\hline $\begin{array}{l}\text { Nelson, P., Bradley, F., } \\
\text { Martindale, A., McBride, A., } \\
\text { \& Hodgson, D. (2019) }\end{array}$ & $\begin{array}{l}\text { To compare how non- } \\
\text { medical roles were being } \\
\text { established in general } \\
\text { practice and understand } \\
\text { barriers, impacts and other } \\
\text { consequences }\end{array}$ & General practice & $\begin{array}{l}\text { Qualitative } \\
\text { comparison }\end{array}$ & $\begin{array}{l}\text { Introducing new roles is complex and } \\
\text { recognising the factors that affect this will help } \\
\text { to align with the goals of general practice and } \\
\text { sustain these roles }\end{array}$ \\
\hline Nuffield Trust (2016) & $\begin{array}{l}\text { To outline the } \\
\text { opportunities and benefits } \\
\text { from developing advanced } \\
\text { practice roles }\end{array}$ & All settings & Research Report & $\begin{array}{l}\text { ACP offers the opportunity to improve clinical } \\
\text { continuity, offer rewarding careers, and fill in } \\
\text { workforce gaps. However, developing the ACP } \\
\text { role can be expensive and in the absence of a } \\
\text { protected title, can open up clinical governance } \\
\text { risks which may inhibit role sustainability }\end{array}$ \\
\hline $\begin{array}{l}\text { Warin, R., Bourne, R., } \\
\text { Borthwick, M., Barton, G., } \\
\text { \& Bates, I. (2016) }\end{array}$ & $\begin{array}{l}\text { To describe the views of } \\
\text { UK critical care } \\
\text { pharmacists on their } \\
\text { advanced practice } \\
\text { education and } \\
\text { accreditation }\end{array}$ & Critical care & Qualitative study & $\begin{array}{l}\text { For pharmacists to progress in advanced practice } \\
\text { in critical care, a national or regional training } \\
\text { programme is required }\end{array}$ \\
\hline $\begin{array}{l}\text { Wright, D., Adams, R., } \\
\text { Blacklock, J., Corlett, S., } \\
\text { Harmston, R., McWilliams, M., } \\
\text { Whyte, S., \& Fleming, G. } \\
\text { (2018) }\end{array}$ & $\begin{array}{l}\text { To describe the most } \\
\text { effective education and } \\
\text { training model for ACP } \\
\text { (pharmacist) in urgent } \\
\text { care, the role evolution } \\
\text { and how to measure their } \\
\text { effectiveness }\end{array}$ & Urgent care & $\begin{array}{l}\text { Longitudinal } \\
\text { qualitative study }\end{array}$ & $\begin{array}{l}\text { Careful consideration of communication and } \\
\text { management ensures integration and role } \\
\text { development }\end{array}$ \\
\hline $\begin{array}{l}\text { Hughes, E., Terry, D., } \\
\text { Huynh, C., Petridis, K., } \\
\text { Ailello, M., Mazard, L., } \\
\text { Ubhi, H., Terry, A., Wilson, K., } \\
\text { \& Sinclair, A. (2017) }\end{array}$ & $\begin{array}{l}\text { To determine if } \\
\text { pharmacists with or } \\
\text { without advanced clinical } \\
\text { practice training could } \\
\text { clinically manage } \\
\text { emergency care attendees }\end{array}$ & Emergency care & $\begin{array}{l}\text { Multi-site, cross- } \\
\text { sectional } \\
\text { observational study }\end{array}$ & $\begin{array}{l}\text { Extended role pharmacists could clinically } \\
\text { manage } 36 \% \text { of emergency department cases, } \\
\text { with greatest potential in general medicine and } \\
\text { orthopaedics }\end{array}$ \\
\hline $\begin{array}{l}\text { Lewis, R., \& Mortimore, G. } \\
\text { (2018) }\end{array}$ & $\begin{array}{l}\text { To differentiate the role of } \\
\text { consultant pharmacist and } \\
\text { ACP (pharmacist) }\end{array}$ & All settings & $\begin{array}{l}\text { Comment article in } \\
\text { peer reviewed } \\
\text { journal }\end{array}$ & $\begin{array}{l}\text { Although similar, the Advanced Pharmacy } \\
\text { Framework (APF) (RPS, 2013) for ACP } \\
\text { (Pharmacists) and consultant pharmacists } \\
\text { slightly varies }\end{array}$ \\
\hline $\begin{array}{l}\text { Bradley, F., Seston, E., } \\
\text { Mannall, C., \& Cutts, C. } \\
\text { (2018) }\end{array}$ & $\begin{array}{l}\text { To investigate the role } \\
\text { evolution and integration } \\
\text { of pharmacists into general } \\
\text { practice }\end{array}$ & General practice & $\begin{array}{l}\text { Longitudinal } \\
\text { qualitative study }\end{array}$ & $\begin{array}{l}\text { There is an expanding patient facing role, } \\
\text { however, barriers such as practice environment } \\
\text { and lack of GP support are noted }\end{array}$ \\
\hline $\begin{array}{l}\text { Seneviratne, R., Bradbury, H., } \\
\text { \& Bourne, R. (2017) }\end{array}$ & $\begin{array}{l}\text { To identify the strategies, } \\
\text { barriers and challenges to } \\
\text { achieving advanced level } \\
\text { practice from advanced } \\
\text { practice critical care } \\
\text { pharmacists }\end{array}$ & Critical care & Qualitative study & $\begin{array}{l}\text { The advanced practitioners require additional } \\
\text { support, by means of a national training } \\
\text { programme. The practitioners required greater } \\
\text { support through mentorship }\end{array}$ \\
\hline $\begin{array}{l}\text { Royal Pharmaceutical } \\
\text { Society [RPS] (2016) }\end{array}$ & $\begin{array}{l}\text { To provide an overview of } \\
\text { career pathways for } \\
\text { pharmacy professionals }\end{array}$ & All settings & $\begin{array}{l}\text { Professional body } \\
\text { report }\end{array}$ & $\begin{array}{l}\text { The foundations and principles of the pharmacy } \\
\text { professional workforce }\end{array}$ \\
\hline
\end{tabular}


The themes were refined to the following: ACP scope of practice and benefits; facilitators, challenges and barriers to ACP role implementation; role implementation and sustainability; and the patient's perspective.

Figure A: PRISMA flow diagram (Moher et al., 2009)

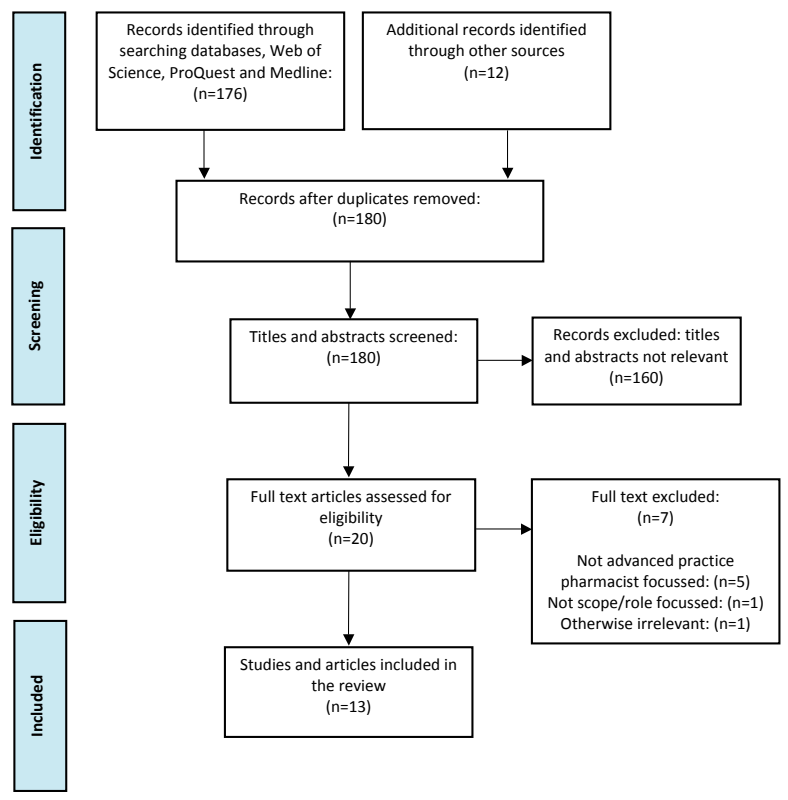

\section{ACP scope of practice and benefits}

All results reported patient-facing roles and discussed the scope of ACP or its benefits to varying degrees, across a variety of healthcare settings. The results describe ACP requiring high-level assessment, autonomy and complex decision-making. Hughes and colleagues (2017) found that pharmacists with advanced practice training could potentially manage $36 \%$ of emergency department cases. The authors concluded that ACP training may be most useful focused on general medicine. This reflected the findings from Wright and colleagues (2018) who concluded that ACPs were most suited to the minor illness area rather than major trauma areas within the urgent care setting. In addition, they suggest that 'ACPs might be able to make a wider contribution, particularly in primary care' (Wright et al., 2018: p.103). Also in agreement, Barnes, Ashraf and Din (2017) state that additional ACP skills lend themselves to pharmacists wishing to undertake a triage or urgent care role. They also highlight in their opinion article, the evolving needs for multi-morbidity and polypharmacy to be managed stating that, 'many of these patients are frail and sensitive to medicines-related problems' (Barnes, Ashraf \& Din, 2017: p.27).
Some results discuss the confusion of the ACP role by patients and other healthcare professionals (HCPs). During interviews with general practice staff in the study by Nelson and colleagues (2019) there were misunderstandings of the ACP role with comparisons, 'like an F2/reg', 'more than a nurse practitioner', and 'between a nurse and GP' being made (Nelson et al., 2019: p.5). This study however, looked further beyond an individual's role expansion and identified 'skill-mix' within the general practice team to address workforce challenges.

In addition to role confusion, Barnes, Ashraf and Din (2017) and Pearce and Breen (2018) both discuss the evolving and expansion of professional roles with pharmacists and nurses respectively. Responding to the argument of ACPs moving away from traditional nursing roles, Pearce and Breen (2018) reflect on their own practice as ACP nurses, explaining that 'many nurses educated to a higher level will not stay within the profession unless nurtured and developed to support job satisfaction' (Pearce \& Breen, 2018: p.445).

The benefits of ACP were discussed in many of the papers with Pearce and Breen (2018), Nuffield Trust (2016) and Hughes and colleagues (2017) citing increased job satisfaction, improved access and care and follow up for patients, cost-effective service provision, and contributing as a versatile, stable part of the workforce. Pearce and Breen (2018) also point out that ACP allows the chance for career pathways to be modernised, for HCPs to practice to their full potential and lead in a changing healthcare system. Interestingly, the Nuffield Trust (2016) describe the positive effect of improving the confidence and competence of other staff after implementing an ACP role.

The issue of utilising an ACP's professional pharmacy background in addition was raised in a few papers. The qualitative evaluation by Wright and colleagues (2018) within an urgent care setting, highlighted the value of the ACP's knowledge of medicines expressed by their colleagues. Barnes, Ashraf and Din (2017) in their opinion article, also theoretically highlight the direct benefit to patients with the addition of skills and knowledge on medicines optimisation.

\section{Facilitators, challenges and barriers to ACP role implementation}

Many of the papers discussed the facilitators, challenges and barriers towards implementing an ACP role. Three studies investigated the outcome of ACP (Seneviratne, Bradbury \& Bourne, 2017; Bradley et al. 2018; Wright et al. 2018) and outlined the lessons learnt from role 
implementation. In addition, The Nuffield Trust (2016) provided feedback from the secondary care case study that it was reporting on. They found that the enablers were: HEE funding, a co-ordinated organisational approach, a strong buy-in and support from clinical champions, strong partnerships with the supporting Higher Education Institutions (HEI), and a strong mentorship and supervision programme. Echoing this, Seneviratne, Bradbury and Bourne (2017) agree that mentorship, structured workplace training and supervision are key enablers to successful role implementation. The study by Wright and colleagues (2018) suggested a variety of facilitators such as the importance of workplace training in addition to HEl education, 'identifying known deficits in pharmacist knowledge and skills', using staff in the department to design an induction process, thereby including colleagues and 'increasing awareness and acceptance' of the ACP role and scope of practice (Wright et al., 2018: p.103). Other recommendations included selecting an individual who is resilient and proactive, providing a supportive mentor and outlining clear lines of responsibility.

In contrast, many challenges are cited in the papers. Both, Nelson and colleagues (2019) and Nuffield Trust (2016) discussed tensions between professional boundaries, with Nuffield Trust (2016) explaining the long history of medical resistance to such roles, however they also suggest that this may fall due to the increasing medical workforce shortages. Discussing the findings from their study, Nelson and colleagues (2019) state, 'some [ACP] trainees reported encountering concerns from GPs and nurses that, 'you're taking our jobs' (ACP Trainee 5, FG1)' (Nelson et al., 2019: p.5). This study also discussed a lack of preparation for ACPs, daunted by the unpredictable and unstandardised nature of general practice, training gaps, and discrepancies between practice expectations and what an ACP could offer.

The urgent care study by Wright and colleagues (2018) reports numerous challenges, for example an ACP's training and education gaps, such as lack of 'red flag' awareness, and an inability to write concisely in the patient notes. The need and value for compulsory workplace training was demonstrated as the ACP course was said to be 'intensive and hard work' and an experienced accident and emergency doctor stated that ACP trainees 'may struggle to obtain all the required knowledge in the time available' (Wright et al., 2018: p.98).

Wright and colleagues (2018) discussed the lack of communication with colleagues of the purpose, structure of training and the rationale of the ACP role. A barrier, felt among many of the papers was the requirement for support, mentorship and supervision which was often difficult to achieve and a cause for frustration. This was a recurrent theme throughout the interviews that Nelson and colleagues (2019) undertook with General Practitioners (GP) staff, with one practice having to withdraw from the study due to their inability to dedicate time to the ACP trainee.

An interesting point was mentioned by the Nuffield Trust (2016) in that there could be a depletion of other parts of the workforce. The paper cites the workforce shortages in nursing, however this is currently not a problem within the pharmacy profession (Wright, 2013). Although with some colleagues being 'sceptical of the new role' (Nuffield Trust, 2016: p.41), another barrier discussed was the increased cost of an ACP (Pharmacist) in comparison to other ACP professions (Wright et al., 2018).

\section{Role implementation and sustainability}

Several of the papers outline either the issues or suggestions when implementing the ACP role. HEE (2017) describes in detail, the key principles when workforce planning such as considering where ACP roles can be best placed to maximise impact, defining clear purpose and objectives for ACP roles, consideration of impact of such roles, ensuring clarity of the service area in which ACPs will work within, ensuring organisational or employer support for the role, and the development of a succession plan for the future workforce.

Nelson and colleagues (2019) describe the implementation of an ACP role in general practice as 'not a simple process' (Nelson et al., 2019: p.1). The study recognises the challenges of colleagues unsure of the scope and purpose of an ACP role, the impact on professional boundaries and the challenge for ACPs to adapt to the often unpredictable and unstandardised nature of general practice. The authors conclude that if new roles such as $A C P$, are to integrate into general practice and ensure role sustainability, they must align with the goals of general practice. In addition, the case study described by the Nuffield Trust (2016) describe the importance of understanding why the ACP role is needed, engaging with stakeholders, ensuring 'buy- in' from the beginning, and the use of clinical champions as advocates.

The results of this review include ACP competency frameworks from the RPS $(2013 ;$ 2016), specific to pharmacists, and HEE (2017) for multi-professional ACPs, described as 'essential' by many of the papers. Lewis and Mortimore (2018) provide a side by side comparison of both frameworks underpinning ACP in England, describing their close resemblance. 
Widely recognised within and beyond healthcare, governance is fundamental to sustainability and the success of ACP (HEE, 2017). Pearce and Breen (2018) and Wright and colleagues (2018) discussed the governance of $A C P$, with both papers highlighting the requirement for a robust governance framework to ensure fitness for practice. In agreement, HEE states, individual and organisational governance need to be robust and within legal, regulatory and professional frameworks' (HEE, 2017: p.13). To ensure role sustainability, HEE (2017) details the necessary aspects of organisational governance and infrastructure arrangements to consider. Examples include regular clinical supervision, and continued assessment against the competency framework.

In agreement to sustain and retain a future ACP role, HEE (2017), RPS (2013), Pearce and Breen (2018), Nuffield Trust (2016) and Nelson and colleagues (2019) all point out the need to evaluate the impact of ACP roles and service user outcome and experience. Nelson and colleagues (2019) state the challenge of this, and similarly with the case study described by the Nuffield Trust (2016), could only gauge impact through anecdotal positive feedback. Within their evaluation, Wright and colleagues (2018) point out that the impact of the role can only be assessed once pharmacists were fully integrated, trained and demonstrating sufficient autonomy. This therefore limited their investigations into the managing, educating and training of an ACP. Nelson and colleagues (2019), whilst interviewing ACPs, found that prescribing rights were perceived by other staff in general practice as an essential skill for the longevity of ACP.

\section{The patient's perspective}

Unfortunately, none of the papers directly relate the patient's perspective with that of ACP (pharmacy). However, it was felt necessary to include, as engaging with patients and carers and considering their opinions have found to be a powerful asset in quality improvement efforts (The King's Fund, 2017). Barnes, Ashraf and Din (2017) quote a survey seeking patients' views on clinical pharmacists in general practice, which received a positive outcome of $70 \%$ of respondents welcoming 'traditional' pharmacist services in general practice. Pearce and Breen (2018) report 'extremely receptive' patients towards ACP (Nursing) consultations in their local environment, with patients describing 'that they were listened to' and 'feeling confident in the outcome of the clinical consultation' (Pearce \& Breen, 2018: p.447). Nuffield Trust (2016) cite a 2009 study that reported increased patient satisfaction when primary care services by doctors were substituted with nurses. The lack of literature evaluating the patients' perspective or outcomes was disappointing yet unsurprising due to the relatively little time the ACP role has had to be fully assessed.

\section{Discussion}

Realising the untapped potential of pharmacy professionals, the advanced practice role, pioneered by the nursing profession is within the early stages of becoming a part of the solution to healthcare workforce problems (Barnes, Ashraf \& Din, 2017). Case studies observing the advanced nurse practitioner (ANP) role and scope of practice well before the HEE framework, state the same reasons for why advanced practice is required today not only in the nursing profession, but also among a variety of HCPs. Reasons cited include a reducing medical workforce and increasing healthcare demands in order to meet such complex demands (Nuffield Trust, 2016).

The reasons for ACP role development and a lack of clarity and scope of practice are also reported to be similar worldwide. For example, the almost exclusively private healthcare system in the United States of America (USA) is vastly different to the publicly-funded NHS, where regulation also varies between states (FIP, 2015). Advanced pharmacy practice in the USA appears less autonomous than in England as in most states, pharmacists may only initiate, modify and continue medication through collaborative drug therapy protocols (CDTP), set between physicians and pharmacists (Murawski et al., 2011). Currently, in very few states, the law does permit pharmacists with additional training to become credentialed as a clinical pharmacist practitioner (CPP) who have prescriptive authority.

The FIP report (2015) highlights that differences are not only between advanced practice roles and healthcare systems, but there are notable differences in education, frameworks and recognition of advanced practice, by way of credentialing and post-nominal letters. The report also highlights the universal need for policies to reflect clear workforce development pathways, along with professional recognition and credentialing.

In Carnwell and Daly's (2003) observation of the ANP role in primary care, they conclude that a career structure and financial reward is essential for a successful ANP role. This lack of structured career pathway for pharmacists, is also expressed by HEE (2019) who state that advanced practice within pharmacy is lamentably not necessarily linked with career progression or employer recognition. Addressing 
this will take time and require larger scale input. There is however international and national interest from professional pharmacy bodies such as the FIP and RPS to develop and drive the advanced practice role. The need for such national and professional bodies to support and regulate ACP is therefore essential as the role continues to develop.

\section{Professional Identity}

Within the literature is the homogenisation of an ACP's professional background and the potential for a loss of professional identity. While recognising the widened scoped of practice, HEE (2019) are explicit that ACPs should be broad-skilled clinicians, yet remain experts in their profession. Applicable to all professions, Nadaf (2018) explains that advanced practice skills should be in addition to nursing skills and not a replacement. Although valid, this may vary depending on the role and sector of care as the skills required and patient group may vary. It may be that advanced practice is more naturally befitting within the nursing profession as some advanced practice skills are an extension or progression of an already experienced nurse. It could be argued that with the estimation of 237 million medication errors per year occurring in England (Elliot et al. 2018), a significant contribution of HCPs with in-depth knowledge of medicines is required in more areas of practice. HEE (2019) agree that alongside traditional skills, training and up-skilling pharmacists to diagnose and treat long term conditions are essential to assure patient safety and manage the complexity.

Although there is a demonstrable interest for pharmacists to undertake ACP qualifications (HEE, 2019), there will also be many pharmacists who do not wish to practice in an ACP role and therefore the 'traditional' pharmacist role will co-exist. It should be recognised that although ACPs are from multi-professional backgrounds, pharmacist's unique selling point is their additional expert knowledge of medicines. This will be of particular use in general practice with the growing number of patients with comorbidities. Multi-morbidity is associated with problematic poly-pharmacy, a risk factor for falls and hospital admission (HEE, 2019). With the increase in this group of patients, the need for a HCP with pharmaceutical expertise is desirable. A case study of an ACP pharmacist demonstrated the successful management of frail and elderly patients during the HEE West Midlands pilot stages of ACP development (HEE, 2015).
In addition to polypharmacy, pharmacists are also expected to play a greater role in other problem areas, such as the rising cost of medicines and the threat of antimicrobial resistance. Although these are areas in which pharmacists have been supporting, key national policies such as The Department of Health and Social Care's five year plan, 'Tackling Antimicrobial Resistance 2019-2024', have now specifically targeted pharmacists within GP surgeries to play a greater role (Andalo, 2019). Likewise, with the increase in elderly patients with comorbidities, pharmacists in general practice play a major role in lowering costs by reviewing medicines use (Dalton \& Byrne, 2017).

\section{Recognition of ACP}

Often a cause of confusion among patients and HCPs alike, many authors report that the historic ambiguity of ACP role and scope of practice is finally becoming clearer with the introduction of a national framework and definition (Pearce \& Breen, 2018). There is a consistent opinion that the HEE framework is a much-needed approach to understand, recognise, and standardise $A C P$, which is often cited as a challenge when implementing such a role (Wright et al., 2018; Nelson et al., 2019). Considering past national healthcare policies highlighted the same issues as today, these developments may be the positive step towards the greater success of an ACP role.

Formal recognition of advanced practice can be achieved by way of credentialing by a professional body such as the RPS or Royal College of Nursing (RCN). Credentialing aims to achieve recognition of a standard of practice and skills, ensure that the role is better recognised, provide assurance to the public and build upon the professional reputation (RPS, 2013). In both pharmacy and nursing professions, those credentialed are not recorded in a separate register by the regulatory bodies, at least in the UK. A voluntary credentialing process carries an additional cost and submission of a portfolio of evidence to meet advanced practice competencies. If the process is not compulsory and not always recognised by employers, credentialing may be viewed as unnecessary, meaningless and a waste of time. These possible deterrents may hinder the much-needed widespread recognition and confidence of the role.

\section{Impact of the Role}

The contribution and impact of the ACP role which was only partially answered by the literature. A study showed 
the potential contribution of ACPs being able to manage around one third of cases presenting in the Emergency Department (Hughes et al., 2017). Benefits of the role were consistent with the reasons for developing the role, which were the provision of flexible models of care where needed, across multi-professions and sectors of care. Several authors suggested ACPs were best suited within primary care roles or roles traditionally provided by primary care providers in secondary care, such as urgent care centres or a minor illness area (Barnes, Ashraf \& Din, 2017; Hughes et al., 2017; Wright et al., 2018).

There was a consensus that the impact of the ACP role since the introduction of the HEE framework could not yet be fully evaluated, however authors often reported positive feedback from patients (Pearce \& Breen, 2018). Other measures such as patient or financial outcomes had not been formally assessed, yet the broad opinion was that measuring impact was fundamental to sustain the role. National relevant bodies such as HEE, Nuffield Trust and The Health Foundation advocate the need for a more sustainable model for funding, developing and implementing advanced practice roles in the pharmacy profession (HEE, 2019). Advantageous for ACPs, workforce transformation will likely be more successful with such backing as it aligns with (UK) national policy.

Considering the nursing profession, a systematic review found that quality of care by nurse practitioners was equivalent to that of a doctor (Horrocks et al., 2002). Specifically within general practice, it was shown that the addition of an ANP resulted in a more effective use of primary care resources and allowed GPs the time to consult patients with more complex needs (Long et al., 2004). McDonnell and colleagues (2012) also found a similar difficulty to the results of this review when evaluating the impact of an ANP. The authors judiciously state that impact may be broader than just on patients, but there may also be an indirect impact which can be difficult to measure, such as influencing the practice of others. In addition, care provided by ANPs can be difficult to differentiate with the contribution made by other team members. The authors also found a variability in ANP roles and scope of practice, therefore difficult to make exact statements of an ANP's impact.

Gerrish, McDonnell and Kennedy (2013) went on to expand their work to develop a framework evaluating the practice of a nurse consultant, using indicators that can be achieved over three domains: clinical, professional and organisational significance. Acknowledging the use of the framework to evaluate ANP roles, the authors point out that further work would be required to establish applicability. This could serve as a starting point to capture ACP impact.

\section{Limitations}

One of the limitations of this review is the minimal published literature surrounding the ACP role specific to pharmacists. As the HEE framework was only recently published in 2017, it will still be some time before these roles are imbedded into practice and can be fully evaluated. In addition, the ambiguity of the term, 'advanced clinical practice' within the literature must also be acknowledged. Despite the selection criteria, the potential for including data where a variation from the scope of practice within the HEE definition of ACP is a limitation. Although ACP is a multi-professional role, observing literature from ANPs may be of slightly less relevance due to professional differences with the nursing and pharmacy profession, such as training and education, governance, and career pathways.

\section{Conclusion}

This integrative review set out to explore the current role, scope of practice and impact of ACP (Pharmacists) considering national policy and recent developments in the recognition and standardisation of ACP. Although the findings were limited to ensure relevance to recent developments with the HEE framework and definition for ACP, the study brought up commonly occurring themes in the literature: the education, development and governance of the ACP role, the benefits, facilitators, challenges and barriers to imbedding the role, and key to sustaining the role, the need for workforce planning and role evaluation. The data however, provided limited formal impact of the role and the patient's perspective, both key aspects towards service improvement.

\section{Future directions}

The ACP role and scope is evolving and if it is to succeed and successfully implemented, there are many factors to consider. The role is appropriate for any setting where it can be seen to benefit and therefore does not restrict or dictate a sector of care or practice. The general practice setting was identified as an ideal setting for ACPs due to a compatible scope of practice. In addition, appropriate mentoring, support and training within the workplace were identified as important factors towards embedding the role. The literature also demonstrated that implementing the role could be facilitated by clear communication with the whole team about the role, scope of practice and implementation plan. It was clear, 
not only within the integrative review results, but also reflected more widely in literature from the nursing profession that for long term success, a business or workforce plan and evaluating the impact of the role are essential.

It is important for an organisational culture regarding attitudes of HCPs to adapt along with the new roles and models of care, through NHS workforce planning.

Guided by experience from the nursing profession, there is a clear need for professional and national bodies to clearly define ACP, the standards for education and training, and professional framework. This is not only to ensure ambiguity of the role is minimised, but also to ensure that ACPs have developed and can evidence underpinning competencies for advanced practice.

Specifically within the pharmacy profession, a clearer route of development is required to maximise the currently under-utilised potential of pharmacy professionals. The requirement for all professions who can become ACPs also need to be clearly represented within the role development. Professional bodies, such as the RPS, must ensure clear pharmacy professional input by working together with HEE.

\section{Future Research}

The HEE framework has shown to be an excellent starting point when defining and standardising ACP. Although challenging, it is essential for ACPs to assess and evaluate the impact of their role.

\section{References}

Andalo, D. (2019). Pharmacists given greater role in government five-year AMR plan. The Pharmaceutical Journal, 302(7922). https://doi.org//10.1211/PJ.2019.20206045

Barnes, E., Ashraf, I., \& Din, A. (2017). New roles for clinical pharmacists in general practice. Prescriber, April, 26-29. https:// doi.org/10.1002/psb.1558

Bradley, F., Seston, E., Mannall, C., \& Cutts, C. (2018). Evolution of the general practice pharmacist's role in England: a longitudinal study, British Journal of General Practice, 68(675), e727-e734. https://doi.org/10.3399/bjgp18X698849

Braun, V., \& Clarke, V. (2006). Using thematic analysis in psychology. Qualitative Research in Psychology, 3(2), 77-101. https://doi.org/10.1191/1478088706qp063oa

Carnwell, R., \& Daly, W.M. (2003). Advanced nursing practitioners in primary care settings: an exploration of the developing roles, Journal of Clinical Nursing, 12, 630-642. https://doi.org/10.1046/i. 1365-2702.2003.00787.x
Casey, M., O'Connor, L., Cashin, A., Smith, R., O'Brien, D., Nicholson, E., O'Leary, D., Fealy, G., McNamara, M., Glasgow, M.E., Stokes, D., \& Egan, C. (2017). An overview of the outcomes and impact of specialist and advanced nursing and midwifery practice, on quality of care, cost and access to services: A narrative review. Nurse Education Today, 56, 35-40. https://doi.org/ $\underline{10.1016 / \text { i.nedt.2017.06.004 }}$

Dalton, K., \& Byrne, S. (2017). Role of the pharmacist in reducing healthcare costs: current insights. Integrated Pharmacy Research and Practice, 6, 37-46. https://doi.org/10.2147/IPRP.S108047

Elliot, R.A., Camacho, E., Campbell, F., Jankovic, D., Martyn St James, M., Kaltenthaler, E., Wong, R., Schulpher, M.J., \& Faria, R. (2018). Prevalence and Economic Burden of Medication Errors in the NHS in England. Available at: http://www.eepru.org.uk/wpcontent/uploads/2018/02/eepru-report-medication-errorfeb-2018.pdf

FIP [Fédération Internationale Pharmaceutique]. (2015). Advanced Practice and Specialisation in Pharmacy: Global Report. (online). Available at: https://www.fip.org/files/fip/Pharmacy Education/Adv_and_Spec_Survey/FIPEd_Advanced_2015_web_v2. pdf

General Pharmaceutical Council. (2019). Standards for the education and training of pharmacist independent prescribers. (online). Available at: https://www.pharmacyregulation.org/sites/ default/files/document/standards-for-the-education-andtraining-of-pharmacist-independent-prescribers-january-19.pdf

Gerrish, K., McDonnell, A., \& Kennedy, F. (2013). The development of a framework for evaluating the impact of nurse consultant roles in the UK. Journal of Advanced Nursing, 69(10), 2295-2308. https://doi.org/10.1111/jan.12116

HEE [Health Education England]. (2015). Advanced Clinical Practice Framework for the West Midlands. (online). Available at: https://www.hee.nhs.uk/sites/default/files/documents/ West\%20Midlands\%20Advanced\%20Clinical\%20Practice\%20Fra mework.pdf

HEE [Health Education England]. (2017). Multi professional framework for advanced clinical practice in England (online). Available at: https://www.lasepharmacy.hee.nhs.uk/dyn/_assets/ folder4/advanced-practice/multi-professionalframeworkfor advancedclinicalpractice inengland.pdf

HEE [Health Education England]. (2019) Advancing pharmacy education and training: a review (online). Available at: https:// www.hee.nhs.uk/sites/default/files/documents/Advancing\%20 Pharmacy\%20Education\%20and\%20Training\%20Review.pdf

Horrocks, S., Anderson, E., \& Salisbury, C. (2002). Systematic review of whether nurse practitioners working in primary care can provide equivalent care to doctors. British Medical Journal, 324(7341), 819-23. https://doi.org/10.1136/bmj.324.7341.819

Hughes, E., Terry, D., Huynh, C., Petridis, K., Aiello, M., Mazard, L., Ubhi, H., Terry, A., Wilson, K., \& Sinclair, A. (2017). Future enhanced clinical role of pharmacists in Emergency Departments in England: multi-site observational evaluation. International Journal of Clinical Pharmacy, 39, 960-968. https://doi.org/ 10.1007/s11096-017-0497-4

Lewis, R., \& Mortimore, G. (2018). Role of the consultant pharmacist in clinical practice. Prescriber, August, 19-22. https:// doi.org/10.1002/psb.1695 
Long, A., McCann, S., McKnight, A., \& Bradley, T. (2004). Has the introduction of nurse practitioners changed the working patterns of primary care teams? A qualitative study. Primary Health Care Research and Development, 5(1), 28-39. https://doi.org/ 10.1191/1463423604pc183oa

McDonnell, A., Gerrish, K., Kirshbaum, M. N., Nolan, M., Tod, A., \& Guillaume, L. (2012). The perceived impact of advanced practice nurses (APNs) on promoting evidence-based practice amongst frontline nurses: findings from a collective case study. Journal of Research in Nursing, 18(4), 368-383. https://doi.org/ $\underline{10.1177 / 1744987112446241}$

Murawski, M., Villa, K.R., Dole, E.J., Ives, T.J., Tinker, D., Colucci, V.J., \& Perdiew, J. (2011). Advanced-practice pharmacists: Practice characteristics and reimbursement of pharmacists certified for collaborative clinical practice in New Mexico and North Carolina. American Journal of Health-System Pharmacy, 68, 2341-2350. https://doi.org/10.2146/ajhp110351

Nadaf, C. (2018). Perspective: Reflections on a debate: When does Advanced Clinical Practice stop being nursing? Journal of Research in Nursing, 23(1), 91-97. https://doi.org/10.1177/1744987117751456

Nelson, P.A., Bradley, F., Martindale, A., McBride, A., \& Hodgson, D. (2019). Skill-mix change in general practice: a qualitative comparison of the three 'new' nonmedical roles in English primary care. British Journal of General Practice, 69(684): e489-e498. https://doi.org/10.3399/bjgp19X704117

Nuffield Trust. (2016). Reshaping the workforce to deliver the care patients need (online). Available at: https://www.nuffield trust.org.uk/files/2017-01/reshaping-the-workforceweb-final.pdf

Officer, T., Cumming, J., \& McBride-Henry, K. (2019). Successfully developing advanced practitioner roles: policy and practice mechanisms. Journal of Health Organization and Management, 33(1), 63-77. https://doi.org/10.1108/JHOM-02-2018-0064

Pearce, C., \& Breen, B. (2018). Advanced clinical practice and nurse-led clinics: a time to progress. British Journal of Nursing, 27(8), 444-448. https://doi.org/10.12968/bjon.2018.27.8.444

RPS [Royal Pharmaceutical Society]. (2013). The RPS Advanced Pharmacy Framework (online). Available at: https://www. rpharms.com/Portals/0/RPS\%20document\%20library/Open\%20access/ Frameworks/RPS\%20Advanced\%20Pharmacy\%20Framework.pdf

RPS [Royal Pharmaceutical Society]. (2016). The RPS Roadmap (online). Available at: https://www.rpharms.com/resources/ pharmacy-guides/professional-developmentguide

Seneviratne, R.E., Bradbury, H., \& Bourne, R.S. (2017). How do pharmacists develop into advanced level practitioners? Learning from the experiences of critical care pharmacists. Pharmacy, 5(38), 1-10. https://doi.org/10.3390/pharmacy5030038

The King's Fund. (2017). Embedding a culture of quality improvement (online). Available at: https://www.kings fund.org.uk/sites/default/files/2017-11/Embedding-cultureQIKings-Fund-November-2017.pdf

Whittemore, R., \& Knafl, K. (2005). The integrative review: updated methodology. Journal of Advanced Nursing, 52(5), 546-553. https://doi.org/10.1111/j.1365-2648.2005.03621.x
Wright, D.J., Adams, R.J., Blacklock, J., Corlett, S.A., Harmston, R., McWilliams, M., Whyte, S., \& Fleming, G. (2018). Longitudinal qualitative evaluation of pharmacist integration into the urgent care setting. Integrated Pharmacy Research and Practice, 7, 93-104. https://doi.org/10.2147/IPRP.S168471

Wright, M. (2013). How many pharmacists is too many? The Pharmaceutical Journal, 291, 177 